\title{
WHITE BLOOD CELLS COUNT AS A PREDICTOR OF BRONCHOPULMONARY DYSPLASIA IN VLBW INFANTS WITH HISTOLOGICAL CHORIOAMNIONITIS
}

\author{
S. Vedovato ${ }^{1}$, C. Peruzzetto ${ }^{2}$, F. Cavallin ${ }^{3}$, D. Trevisanuto ${ }^{1}$, S. Chiarelli ${ }^{4}$, V. Zanardo ${ }^{1}$ \\ ${ }^{I}$ Neonatal Intensive Care Unit, Department of Pediatrics, Padua University, Padua, ${ }^{2}$ Neonatal Intensive \\ Care Unit, Department of Pediatrics, Hospital of Camposampiero, Camposampiero, ${ }^{3}$ Department of \\ Pediatrics, ${ }^{4}$ Department of Oncological and Surgical Sciences (Section of Pathology), Padua University, \\ Padua, Italy
}

Background and aims: Chorioamnionitis is an antenatal inflammatory state: it can induce fetal inflammatory response syndrome and postnatal leukemoid reaction which have been associated to chronic lung disease of preterm infants. The aim of this study was to evaluate if the measure of neonatal WBC, a widely used marker of inflammation, may predict bronchopulmonary dysplasia (BPD) in VLBW infants with histological chorioamnionitis (HCAM).

Methods: During a case-control study on 140 VLBW infants with and without HCAM, admitted to our tertiary referral center, the WBC count was evaluated on day 1, 3, and 6 after birth in 70 VLBW infants with HCAM, comparing newborns with BPD with those without BPD at 36 postmenstrual weeks. Wilcoxon Mann-Whitney test, with Benjamini \& Hochberg correction, was used to assess the association between WBC count and BPD.

Results: In the group of newborns with HCAM and BPD, the WBC count showed an increasing trend from day 1 to day 6. Furthermore, the WBC count was higher in infants with BPD than in those without BPD (Median IQR, WBC $\left(\times 10^{9} / 1\right)$ on day 3: $18.7(14.3-27.4)$ vs $15.9(10-26.8), \mathrm{p}<0.0001$ and on day 6: 30.5 $(20.2-40.2)$ vs 14.9 (9.5-19.2), $\mathrm{p}<0.0007$, while it was not significantly different on day $1: 15.6(6.1-24.6)$ vs $12.5(6.8-20.2), \mathrm{p}>0.05$.

Conclusions: In VLBW infants with HCAM, the WBC count progressively increases in the first week of life. Furthermore, the WBC count on $3^{\text {rd }}$ and $6^{\text {th }}$ day after birth may predict BPD development in VLBW infants with HCAM. 